\title{
Application of biodegradable fluids as liquid insulation for distribution and power transformers
}

\author{
Belén García \\ Electrical Engineering Dpt. \\ Universidad Carlos III de Madrid \\ Madrid, Spain \\ bgarciad@ing.uc3m.es \\ Juan Carlos Burgos \\ Electrical Engineering Dpt. \\ Universidad Carlos III de Madrid \\ Madrid, Spain \\ jcburgos@ing.uc3m.es
}

\author{
Alfredo Ortíz \\ Electrical and Energy Engineering Dpt. \\ Universidad de Cantabria \\ Santander, Cantabria \\ alfredo.ortiz@unican.es \\ Diego García Gómez \\ Electrical Engineering Dpt. \\ Universidad del Valle, \\ Cali, Colombia \\ diego.garcia@correounivalle.edu.co
}

\author{
Carlos Renedo \\ Electrical and Energy Engineering Dpt. \\ Universidad de Cantabria \\ Santander, Cantabria \\ alfredo.ortiz@unican.es \\ Daniel Pérez Rosa \\ Electrical Engineering Dpt. \\ Universidad Carlos III de Madrid \\ Madrid, Spain \\ daperezr@ing.uc3m.es
}

\begin{abstract}
In the last years the use of biodegradable fluids as liquid insulation for distribution and power transformers is becoming more common. The main biodegradable fluids are the natural and synthetic esters, although biodegradable hydrocarbons have been recently proposed as well.
\end{abstract}

Biodegradable fluids have a much lower environmental impact than mineral oil, limiting the risk of soil contamination in case of leaks what makes them a suitable solution for some applications, as off-shore transformers or railway transformers. Additionally, these fluids have higher flash point than conventional mineral oils what reduces dramatically the risk of fire and collateral damage derived from explosion and fire. Despite of these advantageous factors, there are still some aspects that hinders the spread of their use, such as the difference on thermal properties, the lack of accepted maintenance procedures and the price.

This paper presents the current situation of biodegradable insulating fluids, analyzing some of their properties and discussing the aspects that are still to be investigated to make them a real alternative to petroleum-based fluids.

Keywords-Power transformer, distribution transformer, natural esters, synthetic esters, biodegradable liquids

\section{INTRODUCTION}

For more than 100 years mineral oil has been used as liquid insulation for power and distribution transformers. Transformer liquid insulation accomplishes a double mission acting as dielectric material, providing electrical insulation between regions of the transformer at different voltage level, and as a cooling agent that dissipates the heat losses generated in the transformer windings to the ambient. Moreover, the insulating fluid impregnates the solid insulation of the transformer improving the dielectric properties of cellulose and it is also used for diagnosis purposes, since its periodic sampling and analysis is nowadays regarded as a powerful tool for transformer fault detection.

Despite of the good performance and low cost of mineral oils, a recent increase on the environmental and safety requirements have driven the electricity transmission and distribution industry to look for alternatives to this material. Two types of biodegradable liquids are mainly used nowadays as an alternative to mineral oil: Natural Esters, obtained from different vegetable seeds, and Synthetic Ester Fluids.

Funded by European Union's Horizon 2020 Grant 823969 and by Spanish Ministry of Economy DPI2015-71219-C2 2-R.
Ester fluids have three main advantages with respect to mineral oils:

- Esters are biodegradable materials, and then the environmental risk and impact, and the disposal cost of the liquids is minimized. For this reason, these fluids are used in off-shore wind power transformers, urban substations, transformers operating on ships and railway traction transformers.

- The flash point of esters is much higher than that of mineral oils and then the fire risk of ester-filled transformers is dramatically lower. This fact makes ester-filled transformers more suitable for areas near to population or to critical infrastructures. It should be considered that fires in transformers cause every year severe accidents around the world with human losses and destruction of infrastructures.

- Esters are capable to adsorb greater amounts of water than mineral oils allowing the transformer dielectric paper to operate dryer. It has been proven that this has a positive impact in the loss-of-life curve and in consequence on the maximum admissible hottest spot temperature.

On the other hand, esters have some properties that slow down their expansion as an alternative to mineral oils. The viscosity of esters is higher than that of mineral oil and therefore it circulates worse through the cooling channels of the transformer and the temperatures reached at the transformer would be higher. It has been estimated that esterfilled transformers operate within 1 and $3^{\circ} \mathrm{C}$ hotter than similar mineral-oil based units. Additionally, the oxidation rate of esters is higher, especially in the case of natural esters, what make them more suitable for sealed units. Finally, natural esters have a high pour point and then they are not suitable for outdoor transformers in cool zones, unless certain precautions are taken.

\section{FIELD OF APPLICATION OF ESTER BASED TRANSFORMERS}

The use of ester fluids for transformer insulation purposes was proposed in the $90 \mathrm{~s}$ and the first ester-filled distribution and power transformers were installed in 1996 and 2003 respectively [1]. Since then, the use of esters has increased sharply, although the number of units operating around the world is still limited at present.

In [2] a study performed by one of the main suppliers of natural esters for electrotechnical purposes is presented 
which analyses the number of ester-filled transformers operating around the world, classifying them by their power and voltage level. Table I summarizes the data provided in that survey distinguishing between new units, which were originally designed to work with an ester as liquid insulation, and retro-filled units. Retro-filled units are transformers that had been originally designed and operated with mineral oil filling their tank and impregnating its solid insulation, in which the insulating fluid is replaced with an ester. As can be seen in Table I, the number of ester immersed transformers with high powers and voltages is still very low.

TABLE I. NUMBER OF TRANSFORMERS WITH MEDIUM TO HIGH VOLTAGE AND POWER FILLED WITH ESTER FLUIDS AROUND THE WORLD (2014). DATATAKEN FROM [2]

\begin{tabular}{|c|c|c|}
\hline \multirow{2}{*}{$\begin{array}{c}\text { Voltage } \\
(\mathrm{kV})\end{array}$} & \multicolumn{2}{|c|}{ Number of installed units } \\
\cline { 2 - 3 } & New & Retrofilled \\
\hline $\mathbf{4 0 0 - 4 4 9}$ & 1 & 0 \\
\hline $\mathbf{1 5 0 - 1 9 9}$ & $15-20$ & 2 \\
\hline $\mathbf{1 0 0 - 1 4 9}$ & $100-150$ & $20-30$ \\
\hline $\mathbf{3 8 - 9 9}$ & $200-300$ & $30-40$ \\
\hline $\begin{array}{c}\text { Power } \\
\text { MVA) }\end{array}$ & Number of installed units \\
\cline { 2 - 3 } & New & Retrofilled \\
\hline $\mathbf{3 0 0 - 3 4 9}$ & 1 & 0 \\
\hline $\mathbf{2 0 0 - 2 4 9}$ & 3 & 1 \\
\hline $\mathbf{1 0 0 - 1 4 9}$ & $20-30$ & 2 \\
\hline $\mathbf{5 0 - 9 9}$ & $90-100$ & 5 \\
\hline $\mathbf{1 0 - 4 9}$ & $200-300$ & $60-70$ \\
\hline
\end{tabular}

One of the factors that hinders the implantation of esters, especially for bigger units, is that there is still a lack of knowledge on the operation and maintenance practices that must be applied to these actives. Up to date no IEC (International Electrotechnical Commission) Standards have been published in relation with the maintenance and operation of biodegradable filled transformers. The physical and chemical differences between alternative liquids and mineral oil makes compulsory the assessment of these new fluids in comparison with mineral oil before they are widely applied.

\section{DESIGN AND MANUFACTURING PROCESS}

\section{A. Influence of the esters' properties on the design of the thermal and dielectric design of the transformer}

Although numerous studies on the thermal and dielectric properties of ester fluids have been published since the $90 \mathrm{~s}$, the subject remains active nowadays. At present, the focus is mainly put on the influence of temperature and other agents on the fluids' performance and the influence of ageing byproducts on the dielectric strength of the fluids [3-4]. An aspect that has not been sufficiently studied is the difference between the natural ester fluids of different origin. It must be considered that within the term "natural ester" fluids with different basis and different properties are included (i.e. sunflower oil, rapeseed oil, soya oil or hazelnut oil).

Regarding the dielectric design of transformers, the main efforts has been made in comparing the breakdown of esters and mineral oils in case of inhomogeneous fields and different voltage waveforms and the influence of these aspects in the dielectric design of the transformers [5]. As permittivity of the esters is comparable to that of the paper, another important design aspect studied is the probability of creep breakdown. Some works have been presented to understand creepage under a variety of conditions. However more works are necessary to increase the level of confidence of ester filled transformer of high powers, as the oil volumes in that case are larger and the streamer propagation those volumes of ester liquids can compromise the dielectric design of the transformers.

Streamer formation and partial discharges in gas bubbles present in oil have received attention. Analyzing the streamer behavior is important because it allows to understand the prebreakdown phenomena in liquid dielectrics. The streamer behavior of esters and mineral oil is qualitatively similar, but streamers in both cases are very different in the propagation process [7].

A comparison of the impulse $(1.2 / 50 \mu \mathrm{s})$ breakdown voltage of a natural ester and a mineral oil has been carried out by the authors of this work. Both fluids were dried and degasified before the measures. The electrode configuration was needle-sphere and the electrode distances were $10 \mathrm{~mm}$ for positive impulse and $3 \mathrm{~mm}$ for negative impulse. Fig. 1 shows the obtained results fitted to a Weibull distribution. As can be seen, the ester behaves slightly better under positive impulse although the performance is poorer than that of mineral oil for negative impulse. It must be noted that the positive impulse supposes a higher risk for the transformer integrity, as the breakdown voltage values are lower.

The main thermal properties of different biodegradable liquids have been also been compared with those of mineral oil by the authors of the paper in [8]. Table II summarizes some of the obtained results.

\section{B. Impregnation process}

During the impregnation process the solid insulation of the transformer must be adequately dried and subsequently impregnated with the dielectric liquid. The impregnation of the solid insulation with dielectric oil is carried out to eliminate the air that might remain inside the solid insulation. The presence of air weakens the insulation level and favors the appearance of partial discharges that degrade the insulation. By removing most of the gas from the transformer and from the oil the hazard of the small bubbles of gas is highly reduced.

Due to their higher viscosity, natural and synthetic esters might require much longer time to achieve impregnation of the cellulosic materials, used in insulation systems of power transformers [9]. There are very few works which have studied impregnation processes in different solid components of transformers' insulation system even though it is a critical process to obtain a suitable insulation system.

In 1984, researchers from Toshiba Corporation studied the impregnation of transformer board in mineral oil carrying out a theoretical study of the equations that govern the phenomenon [10]. These authors included the capillarity as a variable which influences on impregnation process. Other researchers have carried out studies of board impregnation in mineral oil analyzing the effect of temperature on impregnation time or modeling and validating the 
impregnation process through the measure of breakdown voltage $[11,12]$.
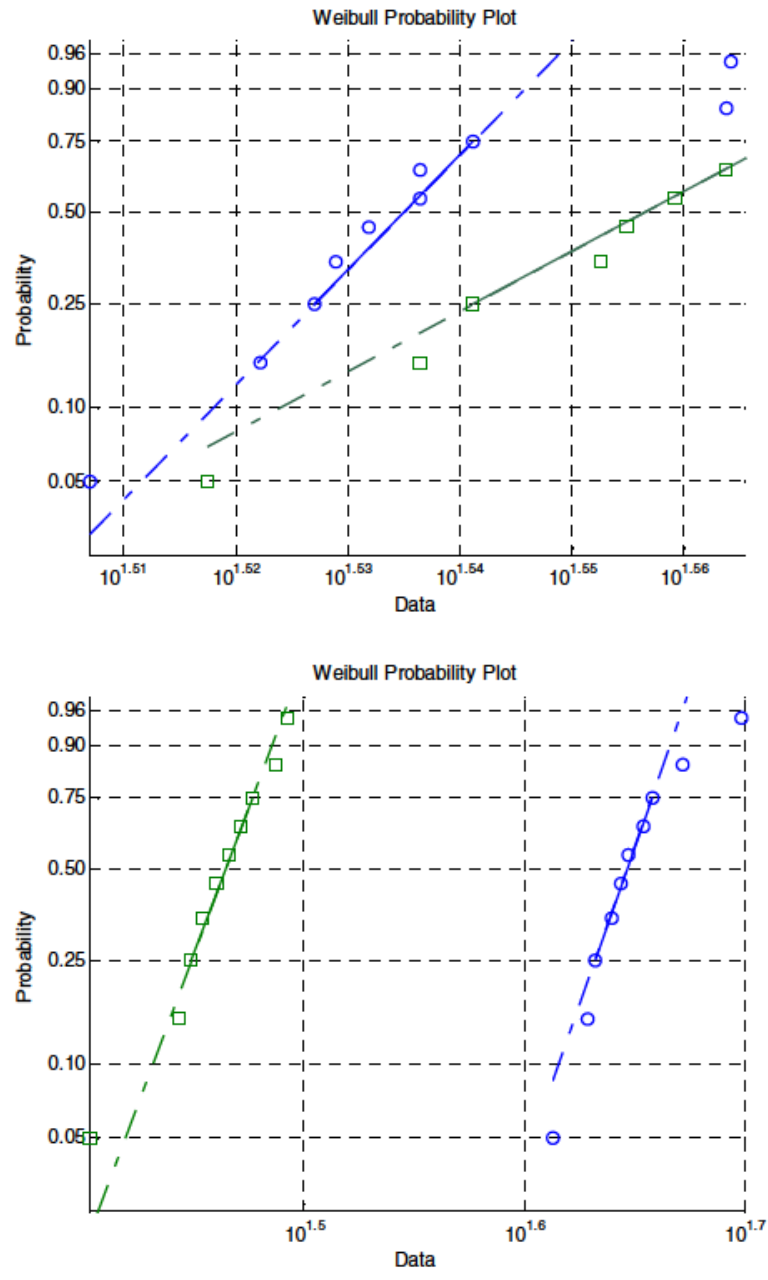

Fig. 1: Positive (top) and negative (bottom) impulse breakdown voltage of a natural ester (green) and a mineral oil (blue)

TABLE II. PROPERTIES OF THE FLUIDS [9]

\begin{tabular}{|l|l|l|l|}
\hline \multicolumn{1}{|c|}{ Property } & Mineral Oil & Natural ester & Synthetic ester \\
\hline$\rho\left(\mathrm{kg} / \mathrm{m}^{3}\right)$ & $\begin{array}{l}1098.72 \\
-0.712 \mathrm{~T}\end{array}$ & $\begin{array}{l}1009.2 \\
-0.653 \mathrm{~T}\end{array}$ & $\begin{array}{l}1085.2 \\
-0.7333 \mathrm{~T}\end{array}$ \\
\hline $\mathrm{cp}(\mathrm{J} /(\mathrm{kg} \cdot \mathrm{K}))$ & $\begin{array}{l}807.163 \\
+3.58 \mathrm{~T}\end{array}$ & $\begin{array}{l}1273.15 \\
+1.952 \mathrm{~T}\end{array}$ & $\begin{array}{l}1242.38 \\
+2.198 \mathrm{~T}\end{array}$ \\
\hline & 0.1509 & $\begin{array}{l}0.1317 \\
+4.14 \mathrm{e} 4 \mathrm{~T}\end{array}$ & $\begin{array}{l}9.71 \mathrm{e}-2 \\
+3.74 \mathrm{e}-4 \mathrm{~T}\end{array}$ \\
$\mathrm{k}(\mathrm{W} /(\mathrm{m} . \mathrm{K}))$ & $-7.101 \mathrm{e}-5 \mathrm{~T}$ & $-8.86 \mathrm{e}-7 \mathrm{~T}^{2}$ & $-7.25 \mathrm{e}-7 \mathrm{~T}^{2}$ \\
& & 7.99 & 0.2556 \\
& 0.0846 & $-6.64 \mathrm{e}-2 \mathrm{~T}$ & $-1.3 \mathrm{e}-3 \mathrm{~T}$ \\
& $-4 \mathrm{e}-4 \mathrm{~T}$ & $+1.84 \mathrm{eT}$ & $+1.68 \mathrm{e}-6 \mathrm{~T}^{2}$ \\
& $+5 \mathrm{e}-7 \mathrm{~T}^{2}$ & $-1.71 \mathrm{e}-7 \mathrm{~T}^{3}$ & \\
\hline & & \multicolumn{3}{|l}{} \\
\end{tabular}

In the last decade the impregnation process of alternative liquids-based transformers has been studied by several authors $[11,12]$. These authors compared the degree of impregnation in a mineral oil, a natural and a synthetic ester finding that the required time to get an adequate impregnation is a function of the viscosity and capillary effect of oil inside cellulose material. It was also found that high temperature can help to overcome the influence of a higher dynamic viscosity of vegetable insulating oil in comparison with mineral oil [11]. Additionally, it was obtained that the time duration for impregnation significantly affects dielectric properties of the natural ester impregnated pressboard such as the capacitance and dielectric dissipation factor [12].

In a recent work [13], the authors of this paper carried out an analysis of the impregnation process of a natural ester in different kinds of paper, Fig 2.

Four different cellulose-based insulation materials were used in the experiments: Crepe, Diamond Dotted Paper (DDP), Kraft and pressboard (PSP 3055) and three different fluids: the mineral oil, natural ester and synthetic ester. The impregnation was carried out in the vacuum oven at $5 \mathrm{mbar}$ and different temperatures to determine its effect, given that both viscosity and surface tension are temperature dependent. For these tests, the papers were cut into $1.5 \mathrm{~cm}$ wide strips and held vertically, with the bottoms immersed in the oil samples. The capillary action occurs when the cohesive intermolecular forces of the liquid are smaller than the interfacial tension between the liquid and surrounding solid surfaces. This physical principle helps us to compare the impregnation speed in the previously listed materials. Fig. 2 represents the impregnation slope of a natural ester in the different kind of papers considered. These models allow predicting the impregnation slope associated to any of these materials for a given temperature. One useful application would be to approximate the temperature at which the esters offer similar impregnation performance as the mineral oil at room temperature.

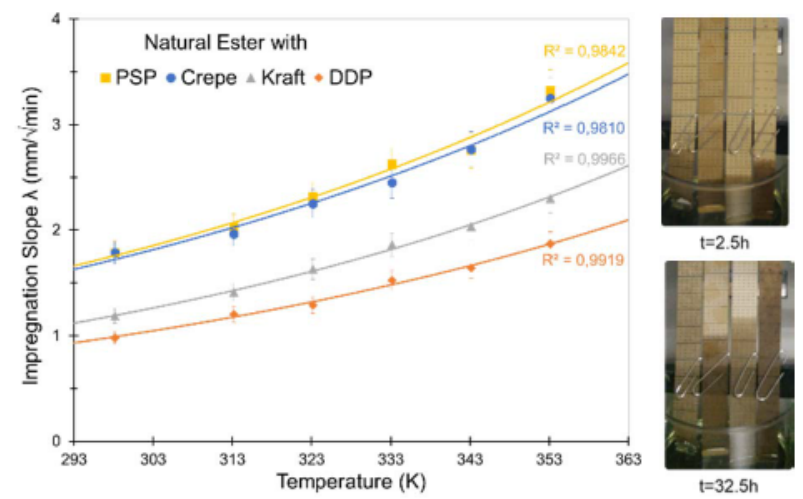

Fig. 2: Impregnation slope of a natural ester in different kind of paper [13]

\section{OPERATION AND MAINTENANCE OF ESTER FILLED TRANSFORMERS}

The maximum admissible load of a transformer is related with the temperature distribution in the transformer for a certain loading profile, and also with the ageing rate of the insulation. Using a natural or synthetic ester to fill the transformer tank may have an impact on both of these factors and in consequence new specific loading criteria must be stablished for ester filled transformers. Work is still necessary on this point.

\section{A. Temperature distribution in ester-filled transformers}

In order to estimate the maximum overload of a power transformer it is critical to estimate the hot-spot temperature (hottest temperature of winding conductors in contact with 
solid insulation or insulating liquid) inside power transformers which is influenced by alternative fluids. The estimation of this temperature is essential because is one of the most critical parameters to estimate the remaining lifetime of solid insulation.

In the literature, some papers can be found where authors numerically predict hot spot temperature and temperature distributions in ester-immersed transformers. For instance, in 2010 Girgis et al. [14] compared the temperatures measured with fiber-optic sensors using alternatively a natural ester and a mineral oil as coolant in a 50 MVA commercial transformer. In 2015 Park et al. [15] employed a 2D Computational Fluid Dynamics (CFD) model in order to obtain temperature and velocity profiles of some alternative liquids used in a distribution transformer of $2.3 \mathrm{MVA}$ and a power transformer of 16.5 MVA. In the same year, Lecuna et al. [16] carried out a 3D CFD simulation of an ONAN distribution transformer comparing a natural ester, a synthetic ester, a high kinematic viscosity silicone oil and a low kinematic viscosity silicone oil with a mineral oil. These works conclude that alternative liquids produce higher temperatures in the transformer windings designed for mineral oil. In [17] a 2D CFD simulation of two vegetal oils in the low voltage winding of a power transformer with zigzag cooling was performed, establishing a comparison of thermal capacity with a mineral oil. Figure 3 shows the average temperature of each disc of the winding for the three liquids studied, where the shape of the described curve for both vegetal oils is close to each other and different from mineral oil as a result of their higher density and viscosity.

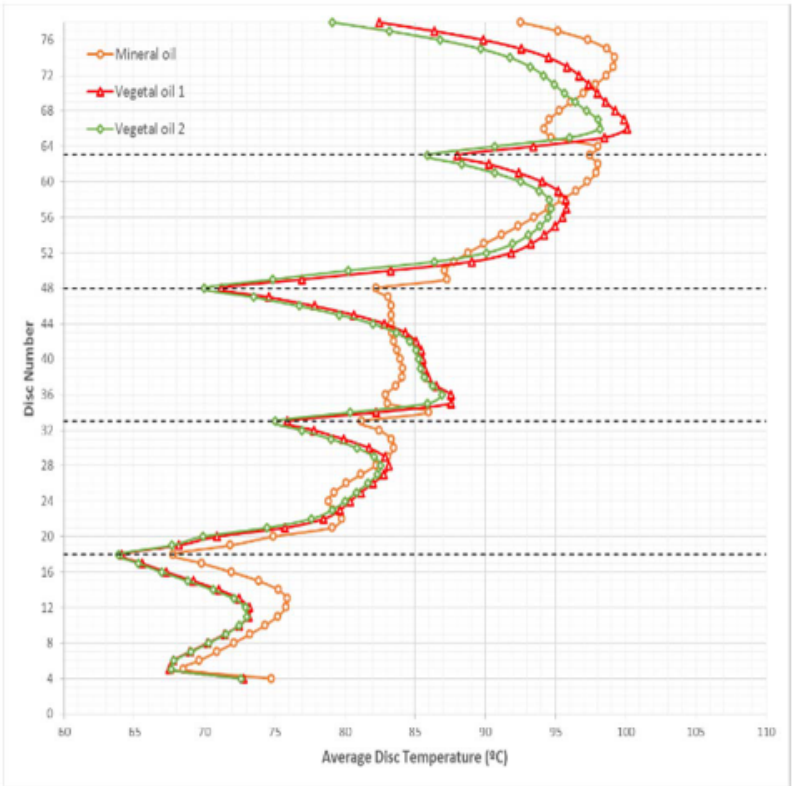

Fig. 3: Average temperature of discs with 5 pass geometry

\section{B. Ageing process of ester impregnated solid insulation using oil analysis}

Temperature has a critical impact on the ageing process of solid insulation. Consequently, it is needed to study the effect of these variables on the thermal degradation of solid insulation immersed in different dielectric liquids (mineral oil, natural and synthetic esters), as the condition of these components determines the lifetime of power transformers. In some research works, kinetic models have been proposed which are generally based on the data obtained from accelerated thermal ageing tests, carried out in laboratory [18-20]. It is important to highlight that commonly laboratory tests are performed at higher temperatures than normal operating temperatures of power transformers, to reduce the time required to obtain representative results. Another main factor that influences the ageing process of solid insulation is the moisture content.

The authors of this work carried out an experimental study [22] aimed at analyzing the impact of the temperature and the moisture content of paper on the ageing rate of transformers insulated with natural esters. Figure 4 shows the results of accelerated ageing tests performed on natural-ester and mineral-oil paper insulation at different temperatures
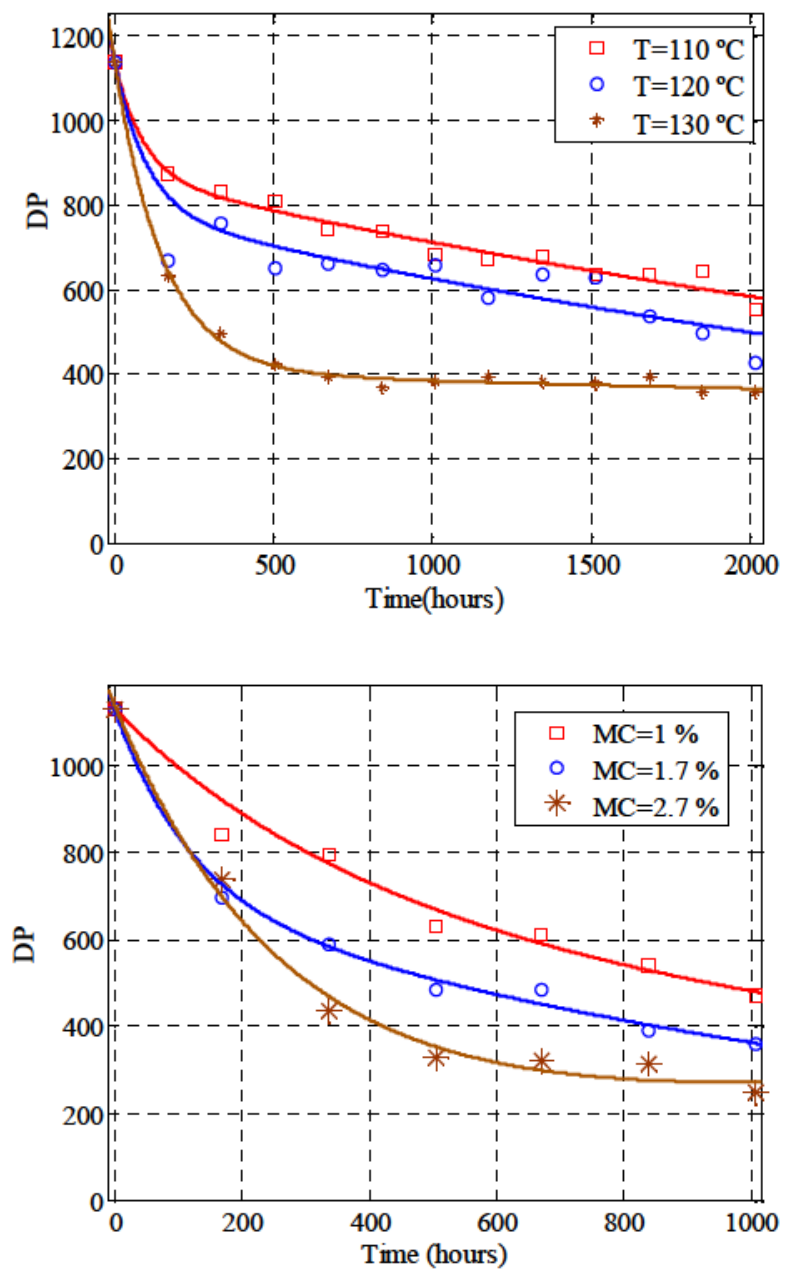

Fig. 4: Ageing process of natural-ester immersed paper (top) and mineral-oil immersed paper (bottom) as a function of temperature. Full study reported in [22]

Fig. 5 compares the effect of the moisture on both kinds of insulation. As can be seen moisture has a lower influence in ester-based insulation than in mineral oil-based insulation. As is explained in [22] the reasons for that lower influence are the transesterification reaction of cellulose, which takes place in presence of an ester, and the hydrolysis reactions in esters. 

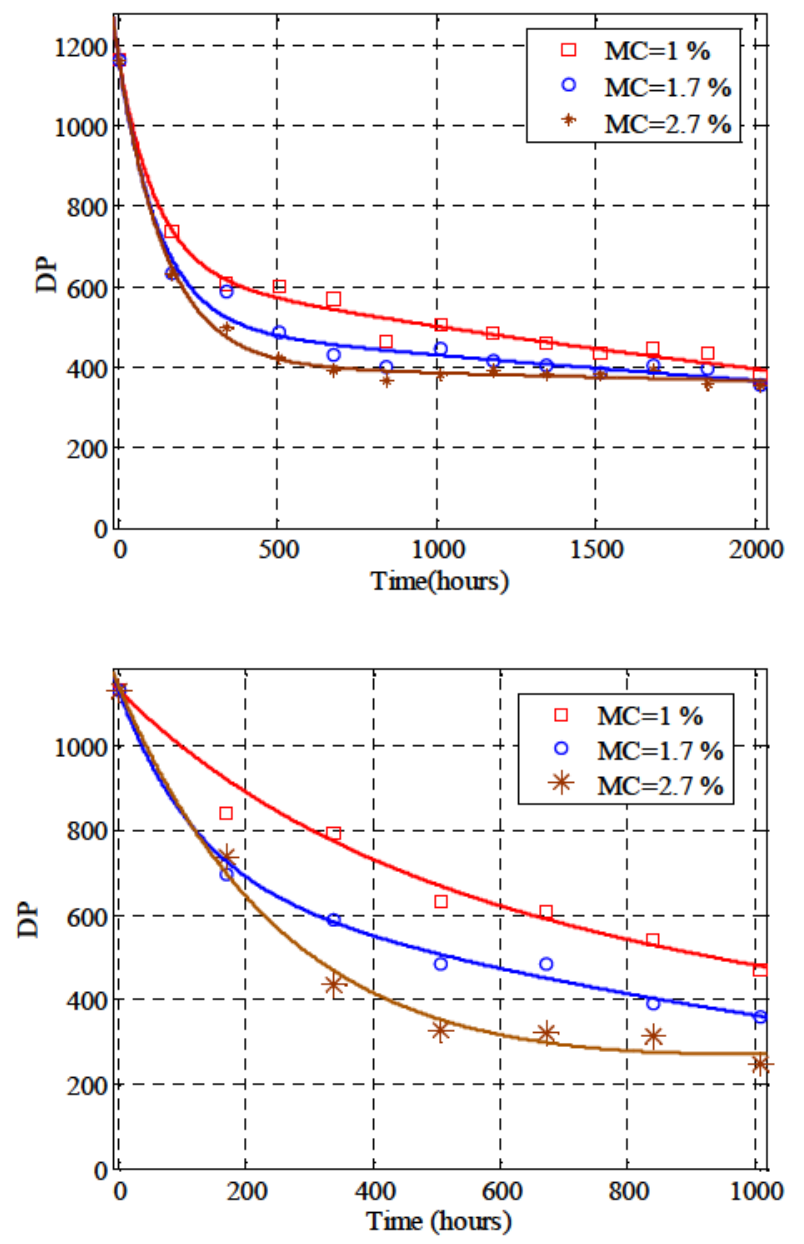

Fig. 5: Ageing process at temperature $130{ }^{\circ} \mathrm{C}$ of a natural-ester immersed paper (top) and mineral oil immersed paper (bottom) a function of moisture. Fully described in [22]

On the other hand, although dielectric properties (breakdown voltage, partial discharge inception voltage, dielectric dissipation factor, relative permittivity, partial discharges...) have been also studied in some works to compare different commercial oils (mineral oil, natural and synthetic esters), most of these studies has been done without thermal ageing [23], so there is still a lack of knowledge about dielectric behavior of biodegradable oils when they have suffered any kind of stress.

\section{Estimation of the ageing condition of ester impregnated solid insulation using oil analysis}

The development of new liquids has required new studies of ageing due to the differences in the molecular structure between esters and mineral oil. The ageing mechanisms of the insulation systems and the ageing by-products are different from mineral ones as it has been found by different authors [23-25].

Findings of these research works have mixed results in terms of the possibility of using these chemical markers (ageing by-products) with ester- based fluids. The chemical markers were measured through either the relevant standard for mineral oil or through in housed developed methods, due to the unavailability of standard techniques about ester-based fluids. The lack of systematic studies and standardized measurement techniques has slowed down the development of condition monitoring techniques for ester filled transformers.

\section{CONCLUSIONS}

The use of biodegradable liquids as liquid insulation of transformers has become more common in the last years. Some properties of these liquids are better that those of mineral oils, such as their fire point and biodegradability. Some other aspects hinder their spread.

In this paper, a revision of the main aspects of ester fluids and their use in transformers is carried out presenting some experimental data to compare their performance with that of mineral oils.

\section{ACKNOWLEDGMENT}

This work was supported in part by the European Union's Horizon 2020 Research and Innovation Programme through the Marie Sklodowska-Curie under Grant 823969, in part by the Ministry of Economy through the National Research Project: Improvement of Insulation Systems of Transformers through Dielectric Nanofluids under Grant DPI2015-71219C2 2-R.

\section{REFERENCES}

[1] "Experiences in Service with New Insulating Liquids". CIGRE Working Group A2.35. October 2010.

[2] K. J. Rapp and J. Luksichn., "Application of Natural Ester Insulating Liquids in Power Transformers." Proceedings of My Transfo 2014, November 2014.

[3] M.H.A. Hamid, M.T. Ishak et al. "Dielectric Properties of Natural Ester Oils Used for Transformer Application Under Temperature Variation". IEEE Int. Conf. on Power and Energy, 2016.

[4] T. Zhao, M. Fan, H. Yue, Y. Liu, Z. Zhang. "Effect of Cellulose Particles on Breakdown Voltage in Wet FR3 Natural Ester". IEEE Acces, Vol 7, 2019

[5] Lashbrook, A. Gyore, R. Martin et al. Design Considerations for the Use of Ester-based Dielectric Liquids in Transmission Equipment. 19th IEEE Int. Conf. on Dielectric Liquids, (2017)

[6] S. Haegele, F.Vahidi, S. Tenbohlen. Investigation of Interfacial Surface Creep Breakdown at Oil-Pressboard Interfaces in Natural Ester Liquid and Mineral Oil. 19th IEEE Int. Conf. on Dielectric Liquid (IDCL). (2017).

[7] A.B. Eriksson, R. Liu, C. Tornkvist. "Differences in Streamer Initiation and Propagation in Ester Fluids and Mineral Oil". IEEE Int. Conf. on Dielectric Liquids, 2011.

[8] A. Santisteban et al, "Thermal Modelling of a Power Transformer Disc Type Winding Immersed in Mineral and Ester-Based Oils Using Network Models and CFD", IEEE ACCESS VOLUME 7, 2019

[9] C. Krause, W. Goetz, B. Heinrich,The impact of drying and oil impregnation conditions and of temperature cycles on the clamping force of power transformer windings, IEEE international Symposium on Electrical Insulation, (2002).

[10] T. Suzuki, M. Takagi, "Oil impregnation in transformer boards (2) theoretical analysis of changes in impregnation depth", IEEE Transactions on Electrical Insulation, 1984.

[11] G. Lu, Q. Huang, H. Song, P. Wu, "Impregnation model and experimental investigation of vegetable insulating oil-paper insulation", ICHVE International Conference on High Voltage Engineering, 2014.

[12] K. Jariyanuratl, S. Maneerot, N. Pattanadech, S. Potivejkul, "Electrical characteristics of natural ester impregnated pressboards under different periods of impregnation", International Conference on Condition Monitoring and Diagnosis, 2016.

[13] O. Sancibrián et al, "Analysis of the Impregnation Process of Cellulosic Materials by Ester-Based Insulating Fluids", Advanced Research Workshop on Transformers, ARWtr 2019, Cordoba

[14] R. Girgis, M. Bernesjo and G.K: Frimpong, "Detailed performance of a 50 MVA transformer filled with a natural ester fluid versus mineral oil, CIGRE session Paris, A2-107, 2010 
[15] T.-W. Park and S. H. Han, "Numerical analysis of local hot-spot temperatures in transformer windings by using alternative dielectric fluids," Electr. Eng., Vol. 97, No. 4, pp. 261-268, 2015.

[16] R. Lecuna, F. Delgado, A. Ortiz, P. B. Castro, I Fernandez, and C. J. Renedo, "Thermal-fluid characterization of alternative liquids of power transformers: A numerical approach," IEEE Trans. Dielectr. Electr. Insul., Vol. 22, No. 5, pp. 2522-2529, 2015.

[17] A. Santisteban, F. Delgado, A. Ortiz, I. Fernández, C.J. Renedo and F. Ortiz, "Numerical Analysis of the Hot-spot Temperature of a Power Transformer with Alternative Dielectric Liquids," IEEE Trans. Dielectr. Electr. Insul., Vol. 24, No. 5, pp. 3226 - 3235, 2017.

[18] W. Wu, Z. D .Wang, A. Revell, P. Jarman, "Computational Fluid dynamics calibration for network modelling of transformer cooling flows - Part II: Pressure loss at junction nodes". IET Electric Power Applications, 6 (1), 28-34, 2012.

[19] N. Lelekakis, D. Martin, J Wijaya, "Ageing rate of paper insulation used in power transformers. part 1: oil/paper system with low oxygen concentration", IEEE Transactions on Dielectrics and Electrical Insulation, 19 (6), 999-2008, 2012.

[20] N. Lelekakis, D. Martin, J. Wijaya, "Ageing rate of paper insulation used in power transformers Part 2: Oil/paper system with medium and high oxygen concentration", IEEE Transactions on Dielectrics and Electrical Insulation 19 (6), 2009-2018, 2012.

[21] M. L. Coulibaly, C. Perrier, M. Marugan, A. Beroual, "Aging behavior of cellulosic materials in presence of mineral oil and ester liquids under various conditions", IEEE Transactions on Dielectrics and Electrical Insulation, 20 (6), 1971-1976, 2013.

[22] B. Garcia, T. Garcia, V. Primo, J. C. Burgos, D. Urquiza, "Studying the loss of life of natural-ester-filled transformer insulation: impact of moisture on the aging rate of paper", IEEE Electrical Insulation Magazine, 33 (1), 15-23, 2017.

[23] U. M. Rao, Y. R. Sood, R. K. Jarial "Performance analysis of alternate liquid dielectrics for power transformers", IEEE Transactions on Dielectrics and Electrical Insulation, 23 (4), 2475-2484, 2016.

[24] S. Y. Matharage, Q. Liu, Z. D. Wang, G. Wilson, C. Krause, "Aging assessment of synthetic ester impregnated thermally non-upgraded kraft paper through chemical markers in oil". IEEE Transactions on Dielectrics and Electrical Insulation, 25 (2), 507-515, 2018.

[25] Z. Wang, X. Wang, X. Yi, S. Li, J. V. Hinshaw, "Gas generation in natural ester and mineral oil under partial discharge and sparking faults", IEEE Electrical 